\title{
PEMETAAN DAN FAKTOR RISIKO SOSIOEKONOMI DAN PERILAKU TERHADAP KEJADIAN PENYAKIT PERIODONTAL DI KECAMATAN PUNDONG KABUPATEN BANTUL
}

\section{MAPPING AND FACTOR OF SOCIOECONOMIC RISK AND BEHAVIORAL OF THE PERIODONTAL DISEASE EVENT IN PUNDONG DISTRICT, BANTUL REGENCY}

\author{
*Prayudha Benni Setiawan, Regina TC. Tandelilin, dan Bekti Nur'aini \\ Program Studi Higiene Gigi Fakultas Kedokteran Gigi \\ Universitas Gadjah Mada
}

Hartono
Fakultas Geografi Universitas Gadjah Mada

Submitted: 07-03-2019; Revised: 22-07-2019; Accepted: 07-08-2019

\begin{abstract}
Periodontal disease is pathological damage that affects the tooth-supporting tissues. Systemic conditions largely influence its pathogenesis. Besides, environmental, socioeconomic, behavioral, environmental and geographic factors can affect individuals experiencing periodontal disease. Geographic Information System (GIS) can be used to analyze the differences of these factors, especially those relating to geographic differences, demographic factors, social, etc. Pundong district has geographical and socio-economic variation. This study aims to describe the distribution of patients with the periodontal disease based on socioeconomic and behavioral factors. The type of study was an observational analytic survey with a cross-sectional design. The subject of research is determined by the Registry Based Study approach where Pundong Community Health Center as the primary data source in this research. The independent variable is periodontal disease, while the dependent variable is a socioeconomic factor and health behavior. Overview of periodontal disease mapping using ArcGIS, with an overlay method or combining two layers, namely the administrative map of Pundong District and coordinates of patients with periodontal disease. Univariate and bivariate analysis using Stata to analyze the distribution and the relationship of each variable. Generalized periodontitis often occurs in Seloharjo. Seloharjo has the most deprived people in Pundong Sub-district. The variables significantly associated with periodontal disease severity were economic status and brushing behavior ( $p$-value <0.05).
\end{abstract}

Keywords: Behavioral; GIS; Periodontal Disease; Socioeconomic.

\footnotetext{
ABSTRAK

Penyakit periodontal adalah kerusakan patologis yang mengenai jaringan pendukung gigi. Patogenesisnya sebagian besar dipengaruhi oleh kondisi sistemik. Selain itu faktor perilaku kesehatan gigi dan sosiekonomi dapat mempengaruhi individu mengalami penyakit periodontal. Sistem

*Corresponding author: prayudha.benni.s@ugm.ac.id

Copyright @ 2020 THE AUTHOR(S).This article is distributed under a Creative Commons Attribution-Share Alike 4.0 International license. Jurnal Teknosains is published by the Graduate School of Universitas Gadjah Mada.
} 
Informasi Geografis (SIG) memiliki fungsi untuk menganalisis faktor-faktor yang berhubungan dengan kondisi geografis, demografis, sosial dan lain-lainnya. Kecamatan Pundong memiliki variasi letak geografis dan sosial ekonomi. Penelitian ini bertujuan untuk menggambarkan distribusi penderita penyakit periodontal dan faktor sosioekonomi dan perilaku berdasarkan kejadian penyakit periodontal. Jenis penelitian ini adalah observasional analitik survei dengan desain cross sectional. Subjek penelitian ditetapkan dengan pendekatan Regristry Based Study di mana Puskesmas Pundong sebagai sumber data dasar dalam penelitian ini. Variabel bebas adalah penyakit periodontal, sedangkan variabel terikat adalah faktor sosioekonomi dan perilaku kesehatan. Peta distribusi kejadian penyakit periodontal dibuat menggunakan software arcgis, dengan metode overlay atau menggabungkan dua layer yaitu peta administrasi Kecamatan Pundong dan koordinat penderita penyakit periodontal. Analisis univariat dan bivariate dengan menggunakan Stata untuk melihat distribusi frekuensi dan hubungan masing-masing variabel penelitian. Hasil penelitian menunjukkan bahwa keparahan penyakit periodontal dengan generalized periodontitis berada di Desa Seloharjo, yang memiliki angka garis miskin terbesar di Kecamatan Pundong. Variabel yang mempunyai hubungan signifikan dengan keparahan penyakit periodontal yaitu status ekonomi dan perilaku menyikat gigi ( $p$-value $<0,05)$.

Kata Kunci:PenyakitPeriodontal; Sosioekonomi; Perilaku; SIG.

\section{PENGANTAR}

Kesehatan gigi dan mulut merupakan bagian yang tidak dapat dipisahkan dengan kesehatan umum. Kesehatan gigi dan mulut yang buruk akan menyebabkan gangguan pada pengunyahan, fungsi bicara dan kepercayaan diri, yang berakibat pada kesehatan pada umumnya. Kesehatan gigi dapat mempengaruhi kesehatan secara umumnya dan dapat menentukan kualitas hidup individu (Petersen, 2003). Hal serupa juga disampaikan oleh Baiju et al. (2017), penyakit mulut memiliki dampak yang bervariasi pada tiap orang mengenai kesejahteraan serta kualitas hidup. Penyakit gigi menyebabkan sakit, ketidaknyamanan, dan penurunan fungsi fisik seperti pengunyahan, berbicara dan dapat mempengaruhi peran sosial individu. Data Riset Kesehatan Dasar (RISKESDAS) pada tahun 2013 menunjukkan prevalensi masalah gigi dan mulut di indonesia secara nasional sebesar 25,9\%. Penyakit karies dan penyakit periodontal merupakan dua penyakit gigi dan mulut yang merupakan masalah utama bagi kesehatan gigi dan mulut di Indonesia. Prevalensi penyakit periodontal pada semua kelompok umur di Indonesia yaitu 96,58\% (Kemenkes, 2013).

Penyakit periodontal terjadi utamanya diakibatkan dari peradangan yang disebabkan oleh invasi bakteri ke dalam periodonsium, tetapi patogenesisnya sebagian besar dipengaruhi oleh kondisi sistemik (Kim et al., 2014). Jenis penyakit periodontal yang sering ditemui adalah periodontitis dan gingivitis. Pada proses perkembangan perjalanan penyakit periodontal, terdapat tiga tahap penting, yaitu pertama terjadi peradangan pada gusi (gingivitis), kedua apabila keadaan ini dibiarkan menjadi kerusakan serabut periodontal yang menyebabkan hilangnya jaringan penyangga yang tidak dapat diatasi (periodontitis), apabila proses ini tidak dihentikan maka tahap ketiga begitu banyak tulang mandibula hilang sehingga ekstraksi elemen gigi geligi tidak dapat dihindarkan (Marcuschamer et al., 2009).

Penampakan secara klinis inflamasi gingiva biasanya akan muncul warna merah hingga kebiruan pada gingiva dan diikuti dengan pembesaran jaringan gingiva yang disebabkan karena edema. Gingiva tersebut akan mudah berdarah apabila diberi stimulasi berupa tekanan seperti menyikat gigi. Secara penampakan klinis, penyakit periodontitis biasanya akan muncul pembengkakan pada papilla interdental disertai inflamasi gingiva hingga penurunan jaringan gingiva dan terbentuknya pocket (Marcuschamer et al., 2009). Keparahan penyakit periodontal dapat diklasifikasikan menurut distibusi, yaitu localized periodontitis dan generalize peridodontitis. Localized periodontitis ditandai dengan kehilangan serabut kolagen pada ligamen periodontal yang melibatkan sekelompok gigi saja, sedangkan generalized aggressive 
periodontitis sudah melibatkan seluruh gigi (Agrawal, 2015).

Penyakit periodontal disebabkan karena adanya interaksi jaringan periodontal dan bakteri. Beberapa penelitian menyebutkan bahwa penyakit periodontal secara etiologi disebabkan oleh beberapa faktor, yaitu faktor sistemik dan local. Faktor sistemik dan faktor lokal memiliki hubungan yang sangat kuat dan menjadi penyebab utama dari kerusakan jaringan periodontal. Akumulasi bakteri plak, tartar dan kalkulus pada gigi merupakan faktor lokal penyebab utama dari penyakit periodontal (Tjahja and Lely, 2005). Selain faktor lokal dan sistemik sistemik, penyakit periodontal dapat diperparah dengan perilaku kesehatan gigi dan sosioekonomi (Kim et al., 2014). Kesehatan yang buruk sering dikaitkan dengan status sosial ekonomi yang rendah. Orang yang tinggal di kondisi ekonomi dan sosial yang buruk cenderung memiliki kondisi kesehatan rendah juga. (Jain et al., 2016). Faktor perilaku kebersihan rongga mulut juga mempengaruhi terjadinya penyakit periodontal. Penelitian Zimmermann et al. (2015), menyebutkan bahwa terdapat beberapa studi yang mengevaluasi hubungan antara frekuensi menyikat gigi dan periodontitis. Beberapa studi crosssectional, terlihat bahwa terdapat asosiasi yang signifikan pada frekuensi menyikat gigi yang rendah dengan nilai peluang 1,4 kali lebih besar mengalami periodontitis dibandingkan individu yang frekuensi menyikat gigi baik.

Persentase penduduk yang memiliki permasalahan gigi dan mulut di Bantul cukup tinggi yaitu 20,7\%, sedangkan persentase perilaku menyikat gigi yang benar di Bantul hanya 5,2 \% (Dinas Kesehatan Yogyakarta, 2009). Kondisi tersebut diperparah dengan pemanfaatan pelayanan kesehatan gigi dan mulut di beberapa wilayah Bantul yang masih rendah, hanya $8 \%$ dari total kunjungan di puskesmas yang memanfaatkan pelayanan kesehatan gigi dan mulut (Ati and Dewanto, 2014). Kondisi tersebut ditambah dengan kondisi sosioekonomi di beberapa Kecamatan Bantul, termasuk Kecamatan Pundong. Menurut Pemerintah Kabupaten Bantul (2016), data potensi kemiskinan Kecamatan Pundong memiliki tingkat kemiskinan cukup tinggi yaitu 30,77\% untuk keluarga prasejahtera dan 22,78\% untuk keluarga miskin.

Manfaat Sistem Informasi Geografis (SIG) pada bidang kesehatan adalah sistem ini dapat memiliki kemampuan untuk menganalisis dan mengelola data-data spasial, terhadap kejadian geografis, lingkungan dan lokasi kejadian penyakit (Nurhayati, 2005). Sistem Informasi Geografis (SIG) adalah alat berbasis komputer yang dapat memfasilitasi pemetaan dan analisis data geografis. Sistem informasi geografis (SIG) juga dapat membantu mengidentifikasi distribusi kasus penyakit dan daerah yang berisiko tinggi (Tiwari et al., 2006). Beberapa penelitian kesehatan gigi sudah menerapkan SIG untuk melihat pemetaan penyebaran penyakit gigi. Seperti penelitian oleh Simone Tetu Moyse et al. (2008), yang menganalisis distribusi trauma gigi anak sekolah di daerah kota Curitiba yang menunjukkan terjadinya perbedaan urban dan sub urban. Penelitian oleh Pereira et al. (2014), yang memetakan kejadian gingivitis pada anak umur 12 tahun, dan melihat hubungan faktor risiko kejadian gingivitis seperti gender, pendapatan, jumlah penghuni rumah, pendidikan dan frekuensi sikat gigi.

Kondisi Kecamatan Pundong yang memiliki keberagaman kondisi geografis dan sosial ekonomi, maka permasalahan yang timbul dalam penelitian ini adalah bagaimana pola distribusi kasus penyakit periodontal berdasarkan faktor sosioekonomi dan perilaku di Kecamatan Pundong dengan menggunakan Sistem Informasi Geografis. Penelitian ini bertujuan untuk menggambarkan distribusi dan mengkaji hubungan penyakit periodontal berdasarkan faktor sosioekonomi dan perilaku di Kecamatan Pundong.

\section{Metode}

Jenis penelitian ini adalah survei analitik dengan desain cross sectional menggunakan Sistem Informasi Geografis untuk mengetahui pola sebaran kasus dan mencari hubungan faktor risiko terhadap penyakit periodontal di Kecamatan Pundong. Penelitian ini telah mendapatkan persetujuan Etik Penelitian 
Fakultas Kedokteran UGM No. KE/FK/0048/ EC/2017. Data yang digunakan dalam penelitian ini terdiri atas data primer dan data sekunder. Data primer diperoleh secara langsung dengan mendatangi responden dan mencatat semua data yang dibutuhkan dalam lembar panduan obeservasi dan titik koordinat lokasi penderita penyakit periodontal yang diidentifikasi dengan menggunakan alat Global Positioning System (GPS).

Data sekunder yang diambil adalah keparahan penyakit periodontal dan jenis kelamin. Subjek kasus dalam penelitian ini adalah seluruh pasien penderita penyakit periodontal pada tahun 2016 di wilayah kerja Puskesmas Pundong sebanyak 152 subjek. Pada penelitian ini dilakukan pemeriksaan dan pengambilan titik koordinat pada masingmasing rumah penderita. Dalam menetetapkan subjek penelitian, peneliti menetapkan kriteria inkusi dan ekslusi. Berikut ini kriteria kelompok inklusi:

a. Penderita penyakit periodontal berdasarkan diagnosis klinis oleh dokter gigi pada catatan rekam medis Puskesmas Pundong tahun 2016.

b. Berdomisili di wilayah Kecamatan Pundong dan menempati rumah atau bertempat tinggal minimal 1 tahun

c. Umur responden 18-56 tahun.

Beberapa kriteria ekslusi kelompok kasus adalah:

a. Ibu hamil yang memiliki penyakit periodontal yang disebabkan oleh hormonal (gingivitis gravidarum).

b. Pasien yang memiliki penyakit periodontal yang bukan disebabkan dari kalkulus.

c. Pasien penyakit periodontal yang memiliki penyakit sistemik seperti diabetes militus tipe 2.

Data sosioekonomi seperti tingkat pendidikan dikategorikan menjadi dua yaitu pendidikan rendah (lulus SMP atau setingkat dibawahnya dengan skor 0) dan pendidikan tinggi (lulus SMA atau setingkat diatasnya dengan skor 1). Data status ekonomi diambil dari laporan data potensi keluarga miskin desa, dikategorikan miskin (0) dan tidak miskin (1).
Data frekuensi menggosok gigi diambil dengan wawancara singkat responden dengan kriteria Baik $(\geq 2)$ Tidak baik $(<2)$. Sedangkan data sekunder diperoleh dari catatan rekam medis kasus penyakit periodontal di Puskesmas Pundong selama tahun 2016 (Januari hingga Desember).

Data yang sudah terkumpul kemudian dianalisis. Peta distribusi kejadian penyakit periodontal dibuat menggunakan software arcgis, dengan metode overlay atau menggabungkan dua layer yaitu peta administrasi Kecamatan Pundong diperoleh dari Bidang Prasarana Wilayah Tata Ruang dan Lingkungan Hidup di BAPPEDA dengan skala 1:25.000 dalam bentuk file shapefile dan koordinat lokasi penderita penyakit periodontal. Analisis univariat dan bivariate dengan menggunakan software Stata untuk melihat distribusi frekuensi dan hubungan masing-masing variabel penelitian pada penelitian ini yakni faktor sosoal ekonomi dan perilaku.

\section{HASIL DAN PEMBAHASAN}

Berdasarkan hasil pengumpulan data tentang jumlah kejadian penyakit periodontal di kecamatan Pundong tahun 2016, didapatkan jumlah penderita periodontal yang menjadi responden dalam penelitian ini sebanyak 152 subjek. Selanjutnya gambaran tentang distribusi atau persebaran kasus untuk setiap wilayah desa/kelurahan di Kecamatan Pundong tersebut dapat dilihat pada tabel 1 dan tabel 2 berikut ini:

Tabel 1

Distribusi Penyakit Periodontal menurut

Desa/Kelurahan di Kecamatan Pundong Tahun 2016

\begin{tabular}{lll}
\hline \multirow{2}{*}{ Desa/Kelurahan } & \multicolumn{2}{c}{ Kasus } \\
\cline { 2 - 3 } & Jumlah & \% \\
\hline Panjangrejo & 40 & 26,32 \\
Srihardono & 47 & 30,92 \\
Seloharjo & 65 & 42,76 \\
\hline Jumlah & 152 & 100 \\
\hline
\end{tabular}

Sumber: Survei Lapangan Penderita Penyakit Periodontal di Kecamatan Pundong Tahun 2016 
Berdasarkan Tabel 1, kejadian penyakit periodontal di kecamatan Pundong terbanyak di Desa Srihardono, dengan distribusi secara berturut-turut adalah Kelurahan Seloharjo sebanyak 65 kasus (42.76\%), Kelurahan Panjangrejo sebanyak 40 kasus $(30,92 \%)$, Kelurahan Srihardono sebanyak 47 kasus $(30,92 \%)$.

Tabel 2

Distribusi Penyakit Periodontal Berdasarkan Keparahan Kasus di Desa Seloharjo, Srihardono dan Panjangrejo Kecamatan Pundong Tahun 2016

\begin{tabular}{lll}
\hline \multicolumn{1}{c}{ Keparahan Kasus } & \multicolumn{2}{c}{ Kasus } \\
\cline { 2 - 3 } & \multicolumn{2}{c}{ Jumlah } \\
\hline Localized Gingivitis Deposit Kalkulus & 82 & 53,95 \\
Localized Periodontitis dengan Deposit Kalkulus & 22 & 14,47 \\
Generalized Periodontitis dengan Deposit Kalkulus & 48 & 31,58 \\
\hline Jumlah & 152 & 100 \\
\hline
\end{tabular}

Sumber: Survei Lapangan Penderita Penyakit Periodontal di Kecamatan Pundong Tahun 2016

Berdasarkan jenis penyakit periodontal, sebagian besar responden mengalami localized gingivitis dengan deposit kalkulus yaitu sebanyak 82 kasus $(53,95 \%)$, sebanyak 48 kasus
$(31,58 \%)$ generalized periodontitis dengan deposit kalkulus, dan 22 kasus $(14,47 \%)$ localized gingivitis dengan deposit kalkulus. Peta distribusi penyakit periodontal di kecamatan Pundong tersebut dapat dilihat pada Gambar 1.

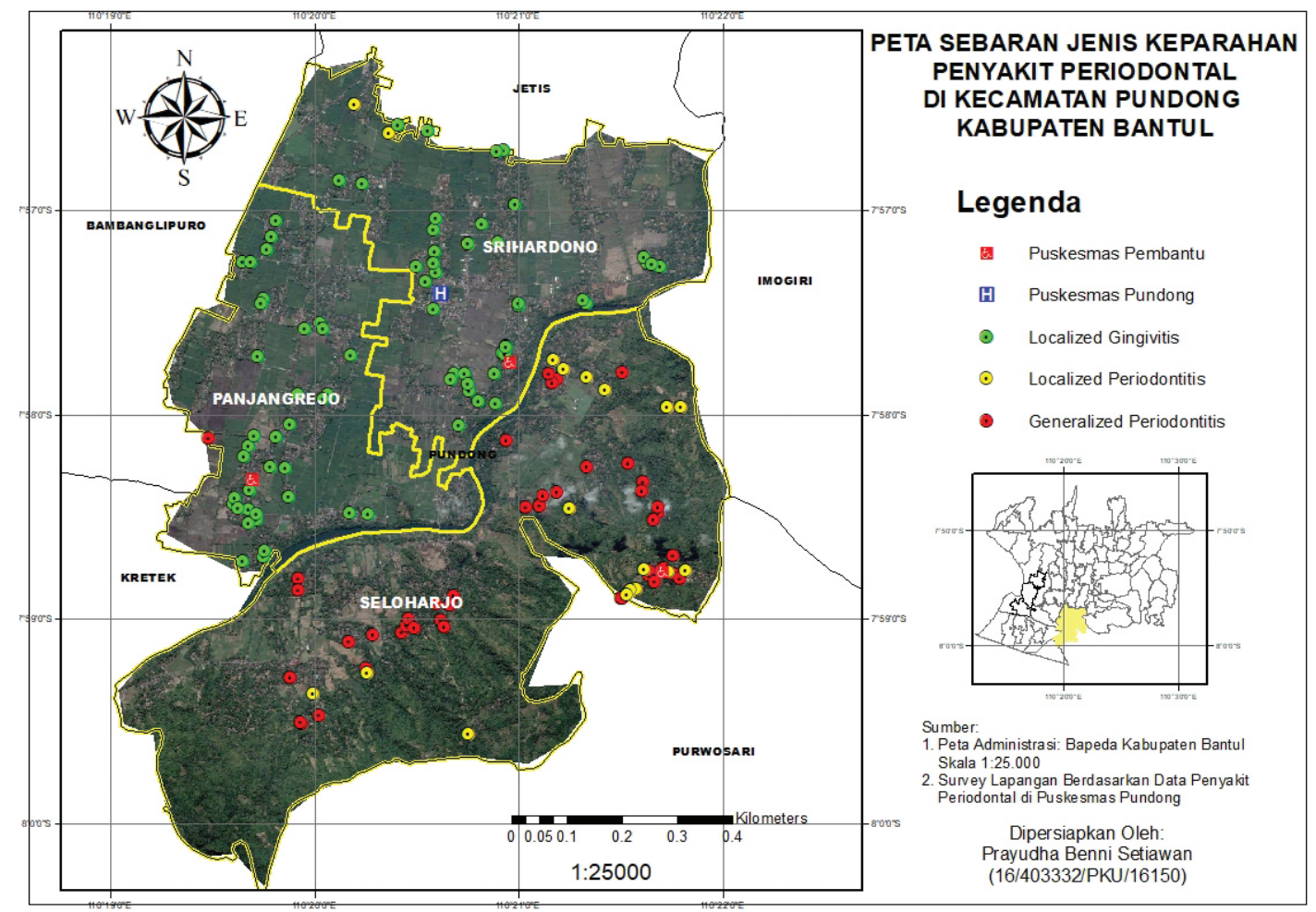

Gambar 1

Peta Sebaran Jenis Keparahan Kasus Periodontal Per Wilayah Administrasi Kecamatan Pundong, Kabupaten Bantul, Daerah Istimewa Yogyakarta

Sumber: Hasil Pemetaan Sebaran Penyakit Periodontal di Kecamatan Pundong Tahun 2016 Berdasarkan Survey Lapangan Menggunakan Software ArGIS 


\section{Faktor Status Ekonomi terhadap Kejadian Penyakit Periodontal}

Gambar1 memperlihatkan bahwa penyakit periodontal dengan keparahan generalized periodontitis (titik merah) mayoritas berada di daerah Desa Seloharjo yaitu 46 orang $(95,83 \%)$. Menurut Pemerintah Kabupaten Bantul (2016), data potensi kemiskinan kecamatan pundong, desa seloharjo memiliki tingkat kemiskinan tertinggi yaitu 640 dari 1470 kepala keluarga (46.93\%). Menurut Gundala dan Chava (2010), melihat hubungan kemiskinan dibandingkan dengan status periodontal, ini menunjukkan terdapat hubungan positif antara kelompok sosial yang lebih tinggi dan status periodontal yang lebih baik. Masyarakat miskin akan mengunjungi pelayanan kesehatan gigi ketika keparahan penyakit sudah terjadi.

Status ekonomi memiliki hubungan dengan keparahan penyakit periodontal. Hasil statistik pada tabel 2 menunjukkan bahwa $p$-value $=0,046(\mathrm{P}<0,05)$, dengan $\mathrm{OR}=2,294$ artinya masyarakat miskin memiliki kesempatan menderita penyakit periodontal dengan tingkat keparahan menyeluruh gigi (generalized) 2,294 kali. Menurut Notohartojo dan Sihombing (2015), hal ini dimungkinkan karena dengan penghasilan yang cukup, dan ada keinginan pada dirinya sendiri untuk melakukan perawatan gigi dan mulutnya. Berbanding terbalik dengan masyarakat miskin, penyakit periodontal sering dijumpai pada individu yang memiliki status sosial ekonomi rendah. Menurut Budiharto (2008), status ekonomi menjadi faktor keluarga dalam memenuhi kebutuhannya, baik kebutuhan primer, sekunder, dan tersier. Kesehatan merupakan kebutuhan primer bagi setiap keluarga, salah satunya adalah memilih pelayanan kesehatan. Status ekonomi keluarga dapat menjadi faktor seseorang dalam memilih kebutuhan kesehatan. Keluarga yang memiliki status ekonomi yang tinggi, salah satunya dapat memilih fasilitas kesehatan yang terbaik, termasuk pelayanan kesehatan gigi dan mulut. Masyarakat berpenghasilan rendah sering menunda kunjungan ke dokter gigi sehingga kondisi kesehatan gigi mereka lebih buruk (Sanders et al., 2006). Hal Ini sesuai dengan penelitian Newman dan Gift (1992), yang mengidentifikasi status ekonomi yang lebih rendah membatasi penggunaan pelayanan gigi. Masyarakat miskin masih belum menganggap berkunjung rutin enam bulan sekali ke klinik gigi sebagai salah satu perilaku pencegahan. Berdasarkan penelitian Darmawan dan Thabrany (2017), tingginya angka dalam penanganan kronis gigi dan mulut di puskesmas, memberi dampak terhadap tingginya pelayanan kuratif dibandingkan pencegahan. Peran puskesmas dan BPJS sangat diperlukan. Kementerian kesehatan, BPJS dan organisasi profesi dokter gigi perlu membuat dan melalukan program pencegahan dan promotif kesehatan gigi yang bersifat intervensi kepada seluruh kelompok masyarakat termasuk kelompok prioritas yaitu high risk. Menurut Dewanto dan Lestari (2014), Era JKN ini, mengharuskan dokter gigi dalam menjalankan profesinya sebagai tenaga kesehatan gigi dapat mengubah paradigma dari kuratif menjadi promotif dan pencegahan. Pola pelayanan saat ini lebih mengutamakan kuratif dan rehabilitatif, dimana masyarakat lebih cenderung akan pergi ke pelayanan kesehatan apabila sudah mengalami sakit gigi. Pola tersebut harus diubah untuk mengupayakan pola pelayanan pencegahan dan promosi terlebih dahulu dibandingkan kuratif kepada seluruh kelompok masyarakat termasuk individu yang memiliki status ekonomi yang rendah. Paradigma tersebut dapat mengubah pandangan masyarakat dalam memotivasi dirinya dalam memperbaiki pola menjaga kesehatan gigi dan mulut. 
Tabel 2

Distribusi Faktor Sosio Ekonomi, Perilaku Berdasarkan Jenis Keparahan

Penyakit Periodontal

\begin{tabular}{|c|c|c|c|c|c|c|c|c|}
\hline \multirow{3}{*}{ Karakteristik } & \multicolumn{4}{|c|}{ Keparahan Penyakit Periodontal } & \multirow{3}{*}{$X^{2}$} & \multirow{3}{*}{ OR } & \multirow{3}{*}{$p$-Value } & \multirow{3}{*}{$95 \% \mathrm{CI}$} \\
\hline & \multicolumn{2}{|c|}{ Generalized } & \multicolumn{2}{|c|}{ (Localized) } & & & & \\
\hline & $\mathbf{n}$ & $\%$ & $\mathbf{n}$ & $\%$ & & & & \\
\hline \multicolumn{9}{|l|}{ Jenis Kelamin } \\
\hline Perempuan & 35 & 72.92 & 76 & 73.08 & \multirow{2}{*}{0} & \multirow{2}{*}{0.991} & \multirow{2}{*}{0.983} & \multirow{2}{*}{$0.430-2.348$} \\
\hline Laki-laki & 13 & 27.08 & 28 & 26.92 & & & & \\
\hline \multicolumn{9}{|l|}{ Pendidikan } \\
\hline Rendah & 14 & 29.17 & 25 & 24.04 & \multirow{2}{*}{0.45} & \multirow{2}{*}{1.301} & \multirow{2}{*}{0.501} & \multirow{2}{*}{$0.553-2.975$} \\
\hline Tinggi & 34 & 70.83 & 79 & 75.96 & & & & \\
\hline \multicolumn{9}{|l|}{ Status Ekonomi } \\
\hline Miskin & 39 & 81.25 & 68 & 65.38 & \multirow{2}{*}{3.97} & \multirow{2}{*}{2.294} & \multirow{2}{*}{0.046} & \multirow{2}{*}{$0.950-5.969$} \\
\hline Tidak Miskin & 9 & 18.75 & 36 & 34.62 & & & & \\
\hline \multicolumn{9}{|l|}{ Menyikat Gigi } \\
\hline$<2$ kali sehari & 24 & 50.00 & 20 & 19.23 & \multirow{2}{*}{15.12} & \multirow{2}{*}{4.2} & \multirow{2}{*}{0.0001} & \multirow{2}{*}{$1.861-9.481$} \\
\hline$\geq 2$ kali sehari & 24 & 50.00 & 84 & 80.77 & & & & \\
\hline
\end{tabular}

Sumber: Analisis Bivariate Penyakit Periodontal Berdasarkan Faktor resiko di Kecamatan Pundong Tahun 2016

\section{Faktor Jenis Kelamin terhadap} Kejadian Penyakit Periodontal

Faktor risiko yang paling umum pada penyakit periodontal adalah jenis kelamin, walaupun secara biologis penyakit periodontal ditentukan secara genetik. Tetapi selama beberapa dekade, beberapa penelitian menyebutkan bahwa perempuan dari segala usia, ras kelompok/ etnis, dan lokasi geografis secara signifikan memiliki penyakit periodontal daripada laki-laki, dinilai oleh prevalensi, lingkup, dan tingkat keparahan, serta parameter dan kasus periodontitis (Genco dan Borgnakke, 2013). Penelitian terdahulu menunjukkan bahwa perempuan memiliki status periodontal yang lebih baik dan perilaku menjaga kesehatan gigi yang lebih positif dibandingkan dengan laki-laki (Sakki et al., 2006).

Berdasarkan Tabel 2, tidak ada hubungan jenis kelamin dengan keparahan penyakit periodontal dengan $p$-value $=0,983(\mathrm{P}>0,05)$, dengan OR=0991 artinya perempuan memiliki kesempatan menderita penyakit periodontal dengan tingkat keparahan menyeluruh gigi (generalized) 0,991 kali, atau perempuan lebih kecil memiliki kesempatan menderita penyakit periodontal dengan tingkat keparahan menyeluruh gigi (generalized). Hal tersebut sesuai dengan penelitian Genco dan Borgnakke (2013), yang menyebutkan bahwa laki-laki dari segala usia, secara signifikan memiliki peluang mengalami penyakit periodontal dibandingkan wanita, dinilai dari prevalensi dan tingkat keparahan. Menurut Krejci dan Bissada (2002), Jenis kelamin merupakan faktor dalam memanfaatkan pelayanan kesehatan. Individu dengan jenis kelamin laki-laki lebih jarang dalam memanfaatkan pelayanan kesehatan dibandingkan individu perempuan. Tingkat responsibilitas individu perempuan dalam menjaga kesehatannya lebih besar dibandingkan laki-laki. Wanita lebih cenderung memperhatikan kondisi kesehatannya, sehingga lebih sering pergi ke pelayanan kesehatan seperti puskesmas untuk mengetahui kondisi kesehatannya (Yustina dan Balqis, 2015).

\section{Faktor Tingkat Pendidikan terhadap Kejadian Penyakit Periodontal}

Kejadian penyakit periodontal berbanding terbalik dengan tingkat pendidikan. Penelitan oleh Taani et al., (2003) menyebutkan bahwa perbandingan antara tingkat pendidikan yang lebih rendah memiliki persentase penyakit periodontal yang lebih tinggi daripada tingkat 
pendidikan yang lebih tinggi. Di Amerika prevalensi penyakit periodontal terjadi pada orang yang memiliki pendidikan kurang dari 12 tahun sebanyak $62 \%$, sedangkan pendidikan lebih dari 12 tahun sebanyak $41 \%$. Penelitian oleh Notohartojo dan Sihombing (2015), dilihat dari faktor pendidikan didapatkan OR sebesar 1,25 artinya subyek berpendidikan tinggi mempunyai peluang 1,25 kali memiliki jaringan periodontal sehat, dibanding responden berpendidikan rendah.

Berdasarkan tabel 2, dengan nilai OR 1,301 menunjukkan artinya pendidikan rendah memiliki kesempatan menderita penyakit periodontal dengan tingkat keparahan menyeluruh gigi (generalized) 1,30, meskipun nilai $p$-value $=0,501 \quad(P>0,05)$. Salah satu faktor sosio ekonomi yang memiliki hubungan terhadap status kesehatan adalah tingkat pendidikan. Tingkat pendidikan dapat mempengaruhi individu dalam bersikap dan berperilaku hidup sehat (Pintauli dan Melur, 2004). Hal tersebut sesuai dengan penelitian oleh Gundala dan Chava (2010), menunjukkan bahwa ada hubungan yang signifikan antara pendidikan dan penyakit periodontal. Hal tersebut menjelaskan bahwa pendidikan yang tinggi berkaitan dengan gaya hidup dan pengetahuan tentang menjaga kesehatan gigi yang kurang serta ketidaktahuan terhadap bahaya penyakit gigi. Menurut Mokoginta et al., (2016), pembentukan perilaku diawali dengan adanya paparan pengetahuan atau informasi bagi individu yang selanjutnya berkembang membentuk sikap dan tindakan. Pengetahuan yang baik dan benar tentang pemeliharaan gigi dan mulut, akan menghasilkan sikap positif terhadap pemeliharan gigi. Salah satu sumber pengetahuan berasal dari pendidikan. Pada setiap tahap pendidikan individu akan memiliki pengetahuan yang berbeda-beda pula. Semakin tinggi tingkat pendidikan seseorang, maka akan semakin mudah untuk menyerap informasi.

\section{Faktor Perilaku terhadap Kejadian Penyakit Periodontal}

Menyikat gigi merupakan salah satu kegiatan pembersihan rongga mulut yang paling sederhana dan efektif. Kegiatan ini antara lain bertujuan membersihkan permukaan gigi dari plak yang menempel. Efektifitas dari penyikatan gigi ditentukan oleh keterampilan menyikat gigi yang meliputi faktor metode, durasi dan frekuensi menyikat gigi (Maruanaya et al., 2015). Penelitian Zimmermann etal., (2015), menyebutkan bahwa terdapat beberapa studi yang mengevaluasi hubungan antara frekuensi menyikat gigi dan periodontitis. Terdapat efek yang jelas diamati, menunjukkan bahwa menyikat gigi yang kurang dikaitkan dengan keparahan penyakit periodontal. Beberapa studi crosssectional, terlihat bahwa terdapat asosiasi yang signifikan pada frekuensi menyikat gigi yang rendah dengan periodontitis. Berdasarkan tabel 2, terdapat hubungan perilaku frekuensi menyikat gigi dengan keparahan penyakit periodontal dengan $p$-value $=0,0001(\mathrm{P}<0,05)$, dengan $\mathrm{OR}=4.2$ artinya frekuensi menyikat gigi kurang dari dua kali sehari memiliki kesempatan menderita penyakit periodontal dengan tingkat keparahan menyeluruh gigi (generalized) 4,2 kali. Beberapa studi crosssectional menyebutkan bahwa terdapat asosiasi yang signifikan pada frekuensi menyikat gigi yang rendah dengan keparahan periodontitis. Hal tersebut kemungkinan disebabkan oleh cara dan waktu menyikat gigi yang tidak diperhatikan. Zaitsuetal. (2017) meneliti tentang hubungan antara parameter perilaku dan status kesehatan mulut, diketahui bahwa faktor yang signifikan terkait dengan keparahan penyakit periodontal adalah frekuensi menyikat gigi yang kurang. Menurut Lertpimonchai et al. (2017), kebiasaan perawatan gigi dan mulut, termasuk menyikat gigi secara teratur dapat mengurangi risiko periodontitis. Frekuensi menyikat gigi yang kurang erat kaitannya dengan oral hygiene buruk meningkatkan risiko periodontitis sekitar dua hingga lima kali lipat dibandingkan dengan $\mathrm{OH}$ yang baik.

\section{SIMPULAN}

Wilayah administrasi desa yang memiliki penderita penyakit periodontal dengan keparahan generalized periodontitis mayoritas berada di desa Seloharjo (95,83\%), di mana desa tersebut memiliki jumlah penduduk 
miskin terbanyak dibandingkan dengan Desa Srihardono dan Panjangrejo. Hasil penelitian menunjukkan bahwa variabel penentu epidemiologi yang berhubungan secara signifikan dengan keparahan penyakit periodontal yaitu status ekonomi, perilaku menyikat gigi dengan $p<0.05$. Berdasarkan hasil tersebut, peran puskesmas dan BPJS diperlukan. Fungsi utama puskesmas adalah mengedepankan upaya promotif dan preventif, kaitannya dengan penyakit periodontal dengan meningkatkan kegiatan pelayanan kesehatan gigi masyarakat. Upaya pencegahan penyakit periodontal yang ditanggung oleh BPJS adalah pembersihan karang gigi satu kali dalam setahun, sedangkan idealnya pembersihan karang gigi dilakukan enam bulan sekali, sehingga BPJS perlu mengkaji ulang pemberian pelayanan dengan pendekatan yang menyeluruh meliputi upaya peningkatan pemeliharaan diri, upaya promotif dan upaya pencegahan kepada seluruh masyarakat utamanya penduduk miskin atau peserta Penerima Bantuan Iuran (PBI).

\section{DAFTAR PUSTAKA}

Agrawal, A. A. (2015). "Gingival enlargements: Differential diagnosis and review of literature". World Journal of Clinical Cases, 3(9): 779. doi: 10.12998/wjcc.v3.i9.779.

Ati, S. R., dan Dewanto, I. (2014). "Gambaran Utilization Rate Pelayanan Kesehatan Gigi Dan Mulut Era Jaminan Kesehatan Nasional Di Puskesmas Piyungan, Banguntapan Ii Dan Banguntapan III Kabupaten Bantul Tahun 2014". Yogyakarta.

Baiju, R., Peter, E., Varghese, N., dan Sivaram, R. (2017). “Oral Health and Quality of Life : Current Concepts", Journal of Clinical and Diagnostic Research, 11(6):21-26. doi: 10.7860/ JCDR/2017/25866.10110.

Darmawan, H., dan Thabrany, I. (2017). “Refleksi Implementasi Jaminan Kesehatan Nasional pada Pelayanan Kedokteran Gigi di Fasilitas
Kesehatan Tingkat Pertama Kota Tangerang Tahun 2017". Jurnal Kebijakan Kesehatan Indonesia, 06(04):174-183.

Dewanto, I., dan Lestari, N. I. (2014) “Panduan Pelaksanaan Pelayanan Kedokteran Gigi Dalam Sistem Jaminan Kesehatan Nasional". Jakarta:PDGI.

Dinas Kesehatan Yogyakarta. (2009). "Riset Kesehatan Dasar Provinsi Di Yogyakarta Tahun 2007". Yogyakarta.

Genco, R. J., dan Borgnakke, W. S. (2013) “Risk factors for periodontal disease", Periodontology (62):59-94. doi: 10.1111/j.1600-0757.2012.00457.x.

Gundala, R., dan Chava, V. K. (2010). "Effect of lifestyle, education and socioeconomic status on periodontal health.", Contemporary clinical dentistry. Wolters Kluwer -Medknow Publications, 1(1):23-6. doi: 10.4103/0976-237X.62516.

Jain, A., Thakur, S., Singhal, P., dan Thakur, P. (2016). "Oral Health Status and Treatment Needs of Children and Young Adult Attending a Day Centre for Individuals with Special Health Care Needs in Shimla", Int J Dent Med Res, 1(6): 32-36. doi: $10.1149 / 2.0121510$ jss

Kemenkes. (2013). “Data Dasar Puskesmas Kementerian Kesehatan Republik Indonesia. Jakarta: Kemenkes". Diakses pada tanggal 31 Maret 2019 http://www.depkes.go.id/ resources/download/pusdatin/ lain-lain/data-dasar-puskesmastahun-2013.pdf.

Kim, D.W., Park, J.C., Rim, T.T., Jung, U.W., Kim, C.S., Donos, N., Cha, I.H. dan Choi, S.H. (2014). "Socioeconomic disparities of periodontitis in Koreans based on the KNHANES IV", Oral Diseases, 20(6):551-559. doi: 10.1111/odi.12168..

Krejci, C. dan Bissada, N. (2002). “Women's Health Issues And Their Relationship 
To Periodontitis", The Journal of the American Dental Association. Elsevier, 133(3): 323-329. doi: 10.14219/JADA. ARCHIVE.2002.0171

Lertpimonchai, A., Rattanasiri, S., ArjOng Vallibhakara, S., Attia, J dan Thakkinstian, A. (2017). "The association between oral hygiene and periodontitis: a systematic review and meta-analysis.", International dental journal. Wiley-Blackwell, 67(6): 332-343. doi: 10.1111/idj.12317

Marcuschamer, E,. Hawley, C.E., Speckman, I., Romero, R.M.D., dan Molina J.N. (2009) "A lifetime of normal hormonal events and their impact on periodontal Health", Perinatol Reprod Hum, 23(2): 53-64.

Maruanaya, A., Mariati, N. dan Pangemanan, D. (2015) 'Gambaran Status Gingiva Menurut Kebiasaan Menyikat Gigi Sebelum Tidur Malam Hari Pada Siswa Sekolah Dasar Negeri 70 Manado', e-GIGI, 3(2).

Mokoginta, R., Wowor, V., dan Opod, H. (2016) 'Pengaruh tingkat pendidikan masyarakat terhadap upaya pemeliharaan gigi tiruan di Kelurahan Upai Kecamatan Kotamobagu Utara', e-GIGI, 4(2).

Newman, J. F., dan Gift, H. C. (1992). “Regular pattern of preventive dental services-a measure of access.", Social science E medicine, 35(8):997-1001. Available at: http:/ / www.ncbi.nlm.nih.gov/ pubmed/1411707 (Accessed: 7 March 2019).

Notohartojo, I., dan Sihombing, M. (2015). "Faktor Risiko pada Penyakit Jaringan Periodontal Gigi di Indonesia (RISKESDAS 2013)", Bulletin Penelitian Sistem Kesehatan, 18(1): 87-94

Nurhayati, S. (2005) Pengembangan sistem informasi pemantauan suplementasi tablet besi ibu hamil berbasis sistem informasi geografis (SIG) studi di
Dinas kesehatan Kabupaten Brebes. Universitas Diponegro.

Pemerintah Kabupaten Bantul. (2016). Rekapitulasi Data Keluarga Miskin Per Desa Kecamatan Pundong. Diakses pada tanggal 7 Maret 2019 http:// simnangkis.bantulkab.go.id/web. php? page $=$ rekap\&kec $=340204$.

Pereira, S., Pardi, V., Cortellazzi, K., Ambrosano, G., Vettorazzi, C., Ferraz, S., De Castro Meneghim, M., dan Pereira, A. (2014). "Geographic information system and multilevel analysis: Gingival status among 12-year-old schoolchildren in São Paulo, Brazil", Revista Panamericana de Salud Publica/Pan American Journal of Public Health, 35(2): 136-143. doi: S1020-49892014000200008.

Petersen, P. E. (2003). “The World Oral Health Report 2003 WHO Global Oral Health Programme", Community dentistry and oral epidemiology, 31 (1): 3-23. doi: 10.1046/j..2003.com122.x.

Pintauli, S. dan Melur, T. (2004). "Hubungan tingkat pendidikan dan skor DMF-T pada ibu-ibu rumah tangga berusia 20-45 tahun di Kecamatan Medan Tuntungan", Dentika dent J, 9(2): 7883.

Sakki, T. K., Knuuttila, M. L. dan Anttila, S. S. (1998). "Lifestyle, Gender and Occupational Status as Determinants of Dental Health Behavior", Journal of Clinical Periodontology, 25(7): 56670. doi: 10.1111/j.1600-051X.1998. tb02489.x.

Sanders, A. E., Slade, G. D., Turrell, G., JohnSpencer, A dan Marcenes, W. (2006). "The shape of the socioeconomicoral health gradient: implications for theoretical explanations", Community Dentistry and Oral Epidemiology, 34(4), pp. 310-319. doi: 10.1111/j.16000528.2006.00286.x.

Taani, D. Q., Habashneh, R., Hammad, M.M., dan Batieha, A. (2003). "The 
periodontal status of pregnant women and its relationship with socio-demographic and clinical variables" , Journal of oral rehabilitation, 30(4):440-5. Available at: http://www.ncbi.nlm.nih.gov/ pubmed/12631171 (Accessed: 5 April 2017).

Tiwari, N., Adhikari, C. M. S., Tewari, A. dan Kandpal, V. (2006). "Investigation of geo-spatial hotspots for the occurrence of tuberculosis in Almora district, India, using GIS and spatial scan statistic.", International journal of health geographics. BioMed Central, 5:33. doi: 10.1186/1476-072X-5-33.
Tjahja, I. dan Lely, M. (2005). “Hubungan Kebersihan Gigi Dan Mulut Dengan Pengetahuan Dan Sikap Responden Di Beberapa Puskesmas Di Propinsi Jawa Barat" Media Penelitian dan Pengegembangan Kesehatan, 15(1).

Yustina, L. dan Balqis, D. (2015). “Factor Relate to Usage With Health Service of Trash Picker in Tamangapa Landfill, Kesehatan Masyarakat Universitas Hasanuddin". Universitas Hasanuddin.

Zaitsu, T., Kanazawa, T., Shizuma, Y., Oshiro, A., Takehara, S., Ueno, M., dan Kawaguchi, Y. (2017). “Relationships between occupational and behavioral parameters and oral health status", industrial health, 55(4):381-390. doi: 10.2486/indhealth.2017-0011. 